\title{
Configurações
}

Revista Ciências Sociais

\section{Estados insulares, agendas políticas e políticas públicas: Os casos de Cabo Verde e São Tomé e Príncipe}

Island states, political agendas and public policy The cases of Cape Verde and Sao Tome and Principe

Les États insulaires, agendas politiques et les politiques publiques : les cas du Cap-Vert et São Tomé et Principe

Aires Bruzaca de Meneses, FERNANDO BESSA RIBEIRO e Artur Cristóvão

\section{OpenEdition}

\section{Journals}

\section{Edição electrónica}

URL: https://journals.openedition.org/configuracoes/1338

DOI: 10.4000/configuracoes. 1338

ISSN: 2182-7419

\section{Editora}

Centro de Investigação em Ciências Sociais

Edição impressa

Data de publição: 1 dezembro 2012

Paginação: 43-68

ISBN: 1646-5075

ISSN: 1646-5075

\section{Refêrencia eletrónica}

Aires Bruzaca de Meneses, FERNANDO BESSA RIBEIRO e Artur Cristóvão, «Estados insulares, agendas políticas e políticas públicas: Os casos de Cabo Verde e São Tomé e Príncipe», Configurações [Online], 10 | 2012, posto online no dia 17 février 2014, consultado o 28 juin 2022. URL: http:// journals.openedition.org/configuracoes/1338; DOl: https://doi.org/10.4000/configuracoes.1338 


\section{Estados insulares, agendas políticas e políticas públicas: Os casos de Cabo Verde e São Tomé e Príncipe}

Island states, political agendas and public policy The cases of Cape Verde and Sao Tome and Principe

Les États insulaires, agendas politiques et les politiques publiques : les cas du Cap-Vert et São Tomé et Principe

Aires Bruzaca de Meneses, Fernando Bessa Ribeiro and Artur Cristóvão

\section{AUTHOR'S NOTE}

$\mathrm{O}$ artigo tem por base dois capítulos da dissertação de doutoramento do primeiro autor, defendida em novembro de 2012 na Universidade de Trás-os-Montes e Alto Douro, sob a orientação dos outros coautores. Respeitando a garantia de confidencialidade assegurada a todos os informantes durante o trabalho de campo levado a cabo pelo primeiro autor, os entrevistados, todos eles ocupando posições relevantes no aparelho de Estado e/ou na sociedade local, são apenas indicados pela sigla cv ou stp, conforme se trate de alguém de, respetivamente Cabo Verde ou São Tomé e Príncipe, n. ํ da entrevista e profissão. Existem ainda dois testemunhos de entrevistados estrangeiros, assinalados pela sigla oi, $\mathrm{n} . .^{\circ} \mathrm{da}$ entrevista, nacionalidade e profissão

\section{Introdução}

1 Colonizados por Portugal, independentes desde 1975, Cabo Verde e São Tomé e Príncipe são dois Pequenos Estados Insulares (PEI), cujos trajetos históricos, composição de classes e dinâmicas sociais endógenas e condições ecológicas diferem substancialmente. A análise 
das políticas públicas desenhadas e colocadas em prática nestes dois países deve considerar estes aspetos, essenciais para se aceder à compreensão das causas que explicam as diferenças, sucessos e, sobretudo, fracassos. Trata-se de proceder à apresentação e discussão da evolução das políticas públicas pós-independência nestes dois Estados insulares africanos, com percursos marcados por dois períodos políticos bem distintos: (i) o primeiro, da independência a finais dos anos 80 do século passado, é caracterizado pela forte presença do Estado na economia e no "comando" da agenda política e das políticas públicas, claramente "emergencial" em Cabo Verde, mais "revolucionário" em São Tomé e Príncipe; (ii) o segundo, em vigor, resulta de uma mudança político-ideológica profunda, reorientando os dois Estados para a democracia parlamentar e a integração plena, ainda que subordinada, na economia capitalista global. De uma forma ou de outra, com dificuldades, erros e desvios, o que estes países perseguiram (e perseguem) é aquilo que Wallerstein justamente assinala em Após o liberalismo: em busca da reconstrução do mundo, quando reflete sobre as causas da opção pelo mercado em detrimento da opção pelo Estado em África e um pouco por toda a periferia: "o que eles esperam conseguir é aquele eldorado fugidio chamado 'desenvolvimento" (2002: 71). Isto é, como parece bem evidente para os casos de Cabo Verde e São Tomé e Príncipe, o que está em causa é a luta contra a pobreza e a construção de políticas públicas que possam contribuir para a melhoria das condições de vida das populações destes dois Estados, sejam elas realizadas através do Estado, do mercado ou mesmo pelas organizações da sociedade civil.

20 artigo começa pelo enquadramento teórico e político-económico dos PEI, apresentando o conceito e refletindo sobre a sua inscrição no contexto global. Como se procura demonstrar, trata-se de um conjunto de países localizados em distintas regiões do globo que, não obstante as numerosas especificidades, partilham elementos comuns que permitem explicar as razões dos seus problemas e dificuldades, em boa medida relacionados com os constrangimentos estruturais impostos pelo sistema mundial e a sua economia-mundo capitalista. Feito este exercício, o texto prossegue com a análise do trajeto pós-independência das políticas públicas em Cabo Verde e São Tomé e Príncipe, procurando mostrar as semelhanças e as diferenças de um processo carregado de lutas e problemas. O objetivo é identificar e compreender as causas explicativas do relativo sucesso de Cabo Verde, improvável aos olhos de muitos aquando da independência, em contraponto com o manifesto fracasso de São Tomé e Príncipe que parecia possuir, quando a presença colonial portuguesa terminou em 1975, melhores condições para ser bem-sucedido na luta pelo desenvolvimento e a melhoria das condições materiais de existência.

3 A fechar a introdução, uma nota para os procedimentos metodológicos utilizados na investigação que suporta o artigo. Tratando-se de um estudo de caráter sociológico e histórico, recorrendo também aos contributos teóricos da ciência política e da economia, a metodologia assentou na combinação de distintas técnicas, a saber: entrevistas semiestruturadas, diálogos informais com registo em caderno de campo e pesquisa em arquivos e outros recursos documentais, permitindo deste modo proceder à triangulação da informação e dados obtidos no contexto, sublinhe-se, de uma investigação plurilocalizada.

4 Privilegiando-se os discursos de atores sociais que ocupam (ou ocuparam) lugares relevantes nos aparelhos estatais ou na investigação, entre os entrevistados em ambos os países contam-se antigos membros do governo, quadros superiores e assessores que, no 
presente ou no passado, desempenham (ou desempenharam) tarefas relevantes no campo das políticas públicas, quer como decisores, quer como investigadores ou técnicos.

\section{Os PEI e a agenda política}

Os PEI são Estados soberanos localizados em ilhas, podendo formar arquipélagos. Embora não exista uma definição consensual, admite-se que são "Estados que [...] possuem uma população inferior a 1,5 milhões de habitantes" (Bass e Dalal-Clayton 1995: 8).2 Apesar de localizados em diferentes regiões - África, Caraíbas e Pacífico, Sul da Ásia, Oceânia - e da sua grande amplitude em termos de dimensão geográfica, podendo atingir até $11.000 \mathrm{Km}^{1}$ (Taglioni 2006: 5), estes Estados apresentam características comuns e confrontam-se com problemas económicos, ambientais e sociais semelhantes, a maioria dos quais de natureza estrutural e que, em boa medida, escapam ao seu controlo. De acordo com o relatório conjunto Commonwealth/BM (www.worldbank.org/smallstates), quase três dezenas de países compartilham as seguintes características: (i) insularidade; (ii) forte exposição a desastres naturais e aos efeitos produzidos pelas mudanças climáticas; (iii) limitada capacidade institucional; (iv) economias abertas e pouco diversificadas; ( $v$ ) dificuldades de acesso ao capital externo. Estas características comuns derivam, sobretudo, "da elevada exposição a fatores externos por parte das suas economias [...], e das suas reduzidas capacidades em se ajustarem a circunstâncias externas em evolução [...]" (Pereira \& Galán 2009: 84). Ou seja, os PEI estão confrontados com sérios problemas de vulnerabilidade socioeconómica, de insularidade e de dependência em relação ao exterior, ditados não só pela sua débil capacidade económica endógena mas também pelo modelo de desenvolvimento imposto pela comunidade internacional.

6 A insularidade é também um conceito que extravasa o campo geográfico, convocando noções como "periferia", “isolamento" e "provincianismo". Está associada a características como "a pequena dimensão, o forte sentimento de identidade local ou insular e o caráter periférico" (Baldacchino apud King 2010: 32). Ainda que o isolamento, quando considerado pela ótica geográfica, seja manifesto para muitos destes Estados, o mesmo não se pode aplicar de forma mecânica ao apontado provincianismo. Devido aos fluxos migratórios e turísticos, muitos habitantes destes países-ilhas são particularmente cosmopolitas e voltados para o exterior. Estes autores defendem igualmente que a perifericidade é uma condição relativa e em permanente mutação, na medida em que "é possível a rápida transformação de um dado espaço periférico em pólos de desenvolvimento de turismo, serviços financeiros ou em centros de investigação de alto nível" (King 2010: 32). Porém, a insularidade, associada à pequenez, não deixa de se constituir em fator constrangedor e de produção de desvantagens, mormente económicas, sociais e ambientais, para o processo de desenvolvimento dos PEI. Deste modo, a insularidade condiciona, em larga medida, o perfil do Estado insular.

7 Os problemas socioeconómicos e ambientais com que se confrontam os cerca de oito milhões de habitantes dos PEI são sobejamente conhecidos. Numerosas são também as declarações e as posições assumidas a nível nacional, regional e internacional sobre as suas múltiplas vulnerabilidades e a procura de soluções. Como aponta Taglioni (2010: 3), "as conclusões de grupos de especialistas da Organização das Nações Unidas (ONU) são recorrentes: as ilhas constituem um grupo mais vulnerável que outros grupos de países em desenvolvimento". Devido a esta situação, a comunidade internacional tem assumido nas últimas décadas um papel dinâmico no sentido de encontrar soluções sustentadas 
para os PEI. Taglioni (2010: 3) destaca as seguintes: (i) a Cimeira do Rio em 1992, que teve como consequência a Conferência de Barbados em 1994, da qual resultou o plano de ação para o desenvolvimento sustentável dos países insulares; (ii) a Cimeira de Maurícias em 2005, na qual se avaliou o cumprimento do plano de ação de Barbados; (iii) a mesa redonda dos países doadores dos PEI sob a égide do BM; (iv) as múltiplas atividades do grupo de trabalho conjunto Commonwealth/BM, que reafirmaram a vulnerabilidade económica dos pequenos Estados em desenvolvimento e particularmente os PEI; $(v)$ as posições da ONU para a Alimentação e Agricultura (FAO) sobre a agricultura, as pescas e a aquacultura; (vi) as posições da ONU para a Educação, Ciência e Cultura (Unesco), que conduziram à criação da International Scientific Council for Island Development (Insula), do programa Man and Biosphere (MAB) e da International Journal of Island Affaires, uma revista científi ca sobre os problemas e desafios dos PEI; (vii) a criação pela ONU da rede de internet para os PEI (SIDSnet).

8 A maioria dos PEI encontra-se situada em zonas geográficas do planeta onde são recorrentes os fenómenos meteorológicos extremos, como é exemplo o tsunami que arrasou, em dezembro de 2004, uma grande parte das zonas costeiras do Oceano Índico. Logo, as catástrofes naturais constituem um dos maiores desafios colocados aos PEI nos seus processos de desenvolvimento. Por sua vez, as secas prolongadas, a escassez de água potável e as doenças endémicas agem também como choques endógenos que afetam a maioria dos PEI e põem em causa os esforços de consolidação das estruturas económicas, ambientais e sociais necessárias ao seu desenvolvimento. O efeito combinado destes fenómenos naturais com outras características específicas dos PEI, nomeadamente a distância em relação aos principais centros internacionais, a pequena dimensão territorial, aliada ao reduzido número de habitantes e de estruturas económicas, sociais e institucionais, constituem para estes Estados aquilo que Brito intitulou de "síndroma dos Pequenos Estados Insulares em Desenvolvimento" (2005: 2).

9 A insularidade é, por tudo isso, um fator determinante no destino dos PEI. Se é certo que, em determinadas circunstâncias, ela pode não constituir uma desvantagem, devido a fatores favoráveis ditados pela situação geoestratégica particular, recursos naturais, liderança política e recursos humanos qualificados (cf. Baldacchino 2008 e King 2010), em regra ela funciona como um escolho severo, sobretudo nos casos em que prevalece a economia de plantação e uma geografia marcada por ilhas distanciadas entre si e dos principais centros internacionais. Por isso, Caillods sugere que "os pequenos Estados arquipelágicos são os territórios onde é possível observar os casos extremos dos efeitos da [...] « insularidade e dispersão espacial e demográfica e alerta contra a tentação de propor soluções idênticas para todos [...]" (apud Tolentino 2006: 38). A insularidade traduz-se, quase sempre, numa forte dependência em relação ao exterior, acrescida de custos elevados, cujos principais centros geradores são o transporte (marítimo e aéreo), a energia, as telecomunicações e os mecanismos internos de distribuição de bens e serviços. ${ }^{2}$ Em suma, a insularidade, acompanhada de fatores como recursos naturais limitados e reduzida dimensão da população, coloca sérios problemas de economia de escala a estes países, além dos custos adicionais relacionados com a separação e o afastamento entre as ilhas que compõem o arquipélago, quando tal se verifica. Como defendeu Jalan, "a pequena dimensão da população ou de emprego pode atuar como um gargalo fundamental na sustentação do crescimento da produtividade do trabalho num pequeno país" (1982: 3). Porém, e prosseguindo com Jalan, "a dimensão é [também] um conceito relativo, porque alguns países podem ser considerados pequenos apenas porque outros 
são maiores" (1982: 42). A questão é saber, sublinha o autor, se o tamanho da nação como um todo é particularmente relevante na compreensão e análise do comportamento dos seus agentes económicos.

Do ponto de vista histórico, os PEI são, na sua grande maioria, um produto do sistema colonial. Segundo King,

desempenharam um papel de subordinados no contexto colonial: o de abastecerem a metrópole de um conjunto pouco diversificado de matérias-primas. Os produtos de plantação típicos ao longo da história foram o açúcar, o algodão, o café, o chá, as especiarias e os minérios preciosos. Esta hiperespecialização persiste nos nossos dias sob a forma de outras monoculturas: os hidrocarbonetos, o turismo ou até as finanças offshore (2010: 43).

11 Os PEI são, pelas razões apontadas, estruturalmente vulneráveis a nível económico, social e ambiental. ${ }^{3} \mathrm{Em}$ termos de vulnerabilidade social, os PEI confrontam-se com preocupações de ordem demográfica, tais como: (i) reduzida dimensão da população ativa, com impactos negativos no crescimento do setor privado; (ii) problemas de migrações; (iii ) êxodo rural, com a concomitante superlotação dos seus centros urbanos e seus impactos sociais e ambientais negativos; (iv) incapacidade de resposta às necessidades de educação, saúde e emprego; $(v)$ graves problemas de segurança alimentar, forçando a importação maciça de alimentos; (vi) crescimento demográfico elevado, colocando sob pressão os sistemas de educação, saúde e habitação.

Sendo evidentes as dificuldades, importa, todavia, relativizá-las e lê-las a diferentes escalas, nomeadamente a nível global. Como sugerem Easterly \& Kraay, "os PEI em média apresentam níveis de produtividade mais elevados, taxas de mortalidade infantil mais baixas e maiores níveis educacionais, quando comparados com países subdesenvolvidos de maior dimensão" (1999: 5). Quanto às vulnerabilidades ambientais, Pereira \& Galán admitem que as mesmas "assumem especial relevância para as ilhas e arquipélagos, quando estes detêm plena consciência de que os seus ecossistemas únicos e biodiversidade são extremamente sensíveis ao desvio ambiental" (2009: 90). Por sua vez, Kaly et al. (2002: 7) apontam que os maiores desafios dos PEI são colocados pelas catástrofes naturais a que muitos deles estão sujeitos de forma recorrente, reduzida sensibilidade ecológica aos efeitos das atividades humanas no território, a que se juntam os problemas ambientais externos, com destaque para os riscos produzidos pela mudança climática a nível global. Estas situações têm concorrido para que não haja respostas sustentadas à síndroma dos PEI, o que tem feito com que o almejado desenvolvimento sustentável traçado para os PEI na Conferência de Barbados, em 1994, há quase duas décadas, ou os Objetivos de Milénio para o Desenvolvimento (OMD) continuem uma aspiração ainda bem distante, face à persistência da crise internacional que atinge o sistema capitalista global ${ }^{4}$. As consequências da insularidade, da pequenez territorial, assim como a suscetibilidade às catástrofes naturais, a capacidade limitada das instituições nacionais, a reduzida diversificação da economia, assim como o afastamento em relação aos grandes centros de comércio internacional, têm colocado sérios problemas às economias dos PEI. A propósito, Briguglio et al. observaram que,

não obstante a grande variação que existe entre os pequenos Estados, na generalidade, as taxas médias de crescimento do PIB dos PEI diminuíram em relação às dos Estados maiores com rendimentos baixos e médios; a instabilidade dos rendimentos e das exportações continua a ser de vulto; a importância do setor de serviços (especialmente o turismo) cresceu, enquanto a da agricultura e das exportações de mercadoria decresceu; as remessas e o investimento direto estrangeiro continuam a ser mais importante para os PEI do que para os seus 
homólogos de maior dimensão; o encargo da dívida aumentou, especialmente nos PEI das Caraíbas (2005: 5).

13 Como resultado desta situação, estes autores afirmaram que os PEI se confrontam com novos desafios, tais como: (i) a perda de preferências pelas exportações tradicionais e a necessidade de diversificação das suas atividades económicas; (ii) a subida dos encargos da dívida; (iii) a degradação ambiental; (iv) o desemprego; (v) a segurança e a criminalidade; (vi) a pandemia do VIH/ sida. Conquanto não se proceda a uma hierarquização destes problemas, há que relevar os relacionados com o ambiente: “com uma menor participação na mudança climática a nível global e na subida do nível do mar, são, porém, estes países que mais sofrem com os seus efeitos perversos" (Chowdhury 2005: 21). Perante este cenário, estes desafios constituem, hoje, as grandes preocupações dos PEI, cuja solução pressupõe um esforço conjunto da parte destes Estados.

14 A dependência atravessa de forma profunda os PEI. Ela manifesta-se, especialmente, pela relação desenvolvimento-subdesenvolvimento, observável através das condicionantes históricos-estruturais que concorrem para a definição da situação de dependência. Entre estas, destacam-se: $(i)$ a redução dos preços dos produtos exportados pelas economias dependentes em relação ao preço dos produtos industriais ou com maior valor agregado, importado dos países centrais (deterioração dos termos de troca); (ii) a remessa dos excedentes dos países dependentes para os países avançados, sob a forma de juros, lucros e amortizações, dividendos e royalties; (iii) a instabilidade dos mercados financeiros internacionais, geralmente manifestada em altas taxas de juros no fornecimento de créditos aos países dependentes (Carcanholo \& Silva 2009: 9).

três condicionantes constituem os marcos fundamentais que presidem às relações entre as economias nacionais dos países subdesenvolvidos e dos países centrais. Em muitos casos, estas relações são materializadas na base de relações de dependência estabelecidas entre grupos sociais dos países centrais e dos PEI. Estas dependências podem ser interpretadas através da vertente nacional-dependente da teoria da dependência, desenvolvida por Bresser-Pereira (2008). Na realidade, muitos destes países "foram colónias [de plantação] desde o século XVI, tornaram-se formalmente independentes em termos políticos, mas continuam a apresentar vários graus de dependência em relação ao centro" (Bresser-Pereira 2008: 12). As suas elites, marcadamente rentistas, procuram articular-se com as elites dos países ocidentais e servem em muitas situações os interesses hegemónicos destes, nomeadamente através da submissão aos ditames das instituições internacionais como o Banco Mundial (BM) e o Fundo Monetário Internacional (FMI). Trata-se de uma relação que, enraizada profundamente no processo de desenvolvimento do capitalismo, se traduz em desvantagens socioeconómicas para os PEI, prejudicando o progresso e o bem-estar das suas populações. Deste modo, o caráter de desenvolvimento capitalista tornou os PEI dependentes, de uma forma geral, dos fluxos financeiros externos, designadamente sob a forma de ajuda ao desenvolvimento, de uma relação comercial muito deficiente e desvantajosa, traduzida em sistemáticas ruturas de stock de importação e da monocultura de exportação de produtos tradicionais ou de recursos e de tecnologias importadas.

Face a este quadro muito desfavorável, será que os PEI estarão condenados a uma posição de submissão aos países centrais e suas políticas? Do ponto de vista da defesa dos seus interesses nacionais, três aspetos devem ser colocados em evidência: (i) a exiguidade do mercado; (ii) a fragilidade do poder de compra das populações; (iii) a grande dificuldade de diversificação da economia. Estes aspetos não deixam de impor limites a estratégias de 
desenvolvimento socioeconómico não-dependente. Se é admissível que estes constrangimentos podem ser parcialmente superados graças ao recurso a uma estratégia de integração nos grandes mercados industrializados, não é possível descartar a possibilidade desta estratégia manter a dependência dos PEI. Até porque esta via de crescimento não está isenta de riscos. São eles: (i) a instabilidade dos preços internacionais das commodities; (ii) a capacidade de intervenção muito reduzida na regulação dos problemas internacionais; (iii) a forte especialização de mercadorias e serviços de exportação; (iv) a insuficiente capacidade de diversificação dos produtos exportáveis; ( $v$ ) os riscos recorrentes de instabilidade das exportações. Em consequência, qualquer estratégia de desenvolvimento terá de adquirir um caráter nitidamente voluntarista e assumir a forma de um programa económico fortemente administrado. Conforme justifica Barbosa,

a pequenez de um país dificulta a exploração de vantagens de economias de escala, fundamentalmente por causa do espaço limitado para a promoção de especializações, dificulta o surgimento de uma administração eficiente, provoca a emigração dos seus quadros e elevados custos nos serviços públicos, tendo em conta a pequena população alvo (2002: 16).

Como consequência das suas vulnerabilidades específicas, a larga maioria dos PEI confronta-se com problemas específicos de subdesenvolvimento e dificuldades socioeconómicas. Tratam-se, particularmente, de situações como: (i) ausência de recursos humanos em quantidade e qualidade para dar resposta adequada aos problemas de desenvolvimento; (ii) fraca capacidade do setor empresarial; (iii) ausência de economia de escala; (iv) falta de recursos financeiros adequados para lidar com os problemas do subdesenvolvimento. Face a esta situação, as agendas políticas da maioria dos PEI são dominadas por projetos e programas normalmente delineados pelas instituições internacionais que operam no campo do desenvolvimento e ajuda aos países periféricos. A uniformidade de critérios na preparação dos programas de luta contra a pobreza que se observa em quase todos os PEI (e nos países subdesenvolvidos de uma forma geral) é um exemplo manifesto da subordinação dos PEI aos ditames dos países ocidentais e às suas políticas neoliberais. Com efeito, as instituições de Bretton Woods desempenham um papelchave não somente no delinear como, em muitos casos, na implementação das agendas políticas e das políticas públicas dos PEI. As resoluções da Conferência de Barbados sobre o desenvolvimento sustentável dos PEI, em 1994, e a programação das metas sobre os Objetivos de Desenvolvimento do Milénio (ODM) adotados pela ONU em 2000 não deixam de ser uma consequência direta e parte integrante da subordinação aos países centrais e seus interesses. No processo de formulação destes programas, os PEI, países recetores da Ajuda Pública para o Desenvolvimento (APD), na sua maioria com níveis de governação frágeis e instituições políticas e administrativas deficientes, foram relegados a um papel secundário.

\section{Aprender a ser independente: a construção de agendas políticas e de políticas públicas em Cabo Verde e S. Tomé e Príncipe na primeira década pós- colonialismo}

18 À data da independência, Cabo Verde e São Tomé e Príncipe debatiam-se com os problemas comuns à generalidade dos outros Estados africanos saídos de longo período de 
dominação colonial: pobreza, saúde e educação debilitadas, situação económica e financeira depauperada, administração pública deficiente e infraestruturas degradadas. Face a isto, não tinham outra alternativa que não fosse o estabelecimento de políticas públicas orientadas para o desenvolvimento a "partir do nada" (Davidson 1988: 153).

Em Cabo Verde, os primeiros dirigentes do país chegaram a ter sérias dúvidas sobre as suas capacidades em darem conta das responsabilidades assumidas. Esta inquietude agravou-se com a seca que teve lugar em 1977, dois anos depois da independência, marcada pela ausência de chuva em todas as ilhas, aliás uma situação recorrente neste arquipélago da África ocidental (cf. Lopes 2002 e Couto 2001). Lopes sublinha que 91\% da população economicamente ativa dependia na sua maioria da agricultura, assegurando o rendimento sobretudo através da realização de trabalhos sazonais. A indústria resumia-se a três ou quatro padarias obsoletas, uma fábrica de tabacos e duas unidades de pesca falidas. Enfim,

o arquipélago ascendia à independência com uma população estimada em 280 mil habitantes, uma economia completamente arruinada, cabendo ao setor terciário comércio, serviços públicos e privados - um predomínio absoluto, aparecendo o Estado como o principal empregador (Lopes 2002: 470).

Em São Tomé e Príncipe a situação não era melhor. Com uma agricultura dominada pela monocultura do cacau, marcada por uma produtividade muito escassa, o país tinha de importar os principais alimentos necessários à dieta humana, como cereais e gorduras vegetais (cf. Menezes 2003: 31). Foi, pois, nestas condições que ambos os países iniciaram o seu trajeto pós-colonial. o primeiro governo de Cabo Verde independente centrou a sua agenda política prioritariamente na necessidade de "combater o desemprego através da reconversão do trabalho precário em atividades económicas socialmente benéficas [e na garantia] do abastecimento à população" (Lopes 2002: 470). Prosseguindo com este autor, o objetivo principal era evitar que a população morresse de fome. Cabo Verde pode ser considerado, neste âmbito, como um país que sobreviveu, entre 1975 e 1990, através de programas de emergência com medidas muito concretas:

um dos primeiros passos importantes dados por Cabo Verde consistiu na criação da Empa ${ }^{5}$ uma empresa de direito público com autonomia administrativa e financeira [já extinta], e que tinha a seu cargo, entre outras funções, a tarefa de comercializar [parte das ajudas doadas] em géneros alimentares destinadas à segurança alimentar em Cabo Verde, cujo resultado das vendas, através de um fundo de desenvolvimento, serviu para financiar os programas de emergência tais como construção de estradas, reflorestação e pagamento de subsídios em várias frentes de trabalho a nível nacional (cv3, economista, técnico aduaneiro).

21 Tratou-se de uma ação de política pública concreta e perfeitamente enquadrável na então situação de penúria que grassava em Cabo Verde. As atividades de caráter social, materializadas através da reciclagem das ajudas alimentares da comunidade internacional, podem ser consideradas como o primeiro grande passo na materialização da agenda política de Cabo Verde no período pós-independência, articulada com a promoção dos vínculos de solidariedade entre os cabo-verdianos, incluindo com os que se encontravam na diáspora:

o estabelecimento de relações saudáveis com as várias comunidades, quer internas

- entre as ilhas -, quer externas - comunidades emigradas espalhadas pelo mundo

-, foi outra ação política do Estado de Cabo Verde que funcionou como prova de coesão existente em torno da nação cabo-verdiana, através da manifestação de um forte sentimento de pertença e de uma solidariedade que não tem apenas o valor psicológico, mas também uma tradução económica justificada pelas remessas, tanto 
oficiais, como através de mecanismos informais existentes entre as diversas comunidades e as ilhas, constituindo deste modo uma componente segura e permanente da economia cabo-verdiana (cv1, investigador).

Deste modo, com o apoio financeiro da comunidade internacional e parte de recursos financeiros provenientes das remessas dos emigrantes, Cabo Verde inicia um processo dinâmico e estruturado de formação de capital humano e de constituição de instituições e empresas públicas, procurando responder a um cenário muito difícil:

Com uma taxa de analfabetismo superior a $60 \%$, uma grande carência de infraestruturas escolares, dois liceus para 10 ilhas, escolas do ensino básico muito distantes umas das outras, inexistência de escolas no interior das ilhas, com a presença de muitas famílias monoparentais, com apenas uma escola técnica para dez ilhas, ausência total do ensino profissional e superior e com a agravante da insularidade, fome e seca, a situação de ausência de bem-estar dos cabo-verdianos não podia ser mais desoladora (cv6, deputada).

Este processo permitiu a revitalização do tecido económico e social cabo-verdiano, assim como o lançamento das bases para a construção do novo Estado. Ocupando o desenvolvimento da educação um lugar incontornável (v. Cardoso 2007), procurou-se ampliar, apesar de todas as insuficiências, o papel do funcionalismo público já existente no tempo colonial, como justamente assinala A. Pereira (2003: 53-54). Conquanto não se tenha descurado outros campos, como a saúde, a educação foi considerada como o elemento mais precioso de todo o processo de edificação socioeconómica do Estado em Cabo Verde, tendo o país aproveitado os recursos humanos existentes e os meios colocados à sua disposição pela comunidade internacional nessa altura. Dito por outras palavras,

Cabo Verde fez, desde o início da construção do Estado independente, uma aposta clara e desmesurada na educação. A partir daí pode-se explicar todo o resto. Esta aposta produziu uma camada de dirigentes bem formados. É óbvio que o ponto de partida de Cabo Verde, a independência, já nessa altura, era diferente em relação a São Tomé e Príncipe. Se é verdade que, nessa altura, Cabo Verde era um país potencialmente com muito menos recursos que São Tomé e Príncipe, por outro lado, em termos daquilo que importa à nação, já naquela altura, e mesmo em relação a todos os outros PALOP, era o país mais rico em termos de recursos humanos. É isso que faz um país e essa é uma grande diferença entre estes dois Estados. Os recursos humanos constituem um recurso que o Estado de Cabo Verde nunca deixou de potencializar e aproveitar da forma mais racional possível (oi1, português, diplomata e professor universitário).

Cabo Verde revelou também capacidade para agendar e elaborar políticas públicas capazes de fazer face aos problemas de desenvolvimento económico. Isso não seria possível sem um quadro mínimo de recursos humanos endógeno, sem o financiamento da comunidade internacional através da APD, de empréstimos concessionais e sem as remessas dos seus emigrantes espalhados pelo mundo. Foi com estes meios que Cabo Verde obteve os recursos para investimentos nos setores de desenvolvimento rural e pescas, transportes e comunicações, administração pública e turismo. Este último setor ganhou projeção a partir da década de 1980, acabando por se tornar no mais dinâmico da economia cabo-verdiana, assumindo-se nos anos subsequentes como "o vetor estratégico da inserção ativa na economia mundial e como uma fonte potencial de acumulação de recursos" (cv3, economista, técnico aduaneiro). A materialização, relativamente eficiente, destas opções, faz hoje toda a diferença em relação a São Tomé e Príncipe, pois permitiu criar as condições para um progressivo e sustentado crescimento da economia em Cabo Verde. Traduzidas em políticas públicas bem-sucedidas, estas opções contribuíram para a 
mudança da imagem de "país inviável" que a comunidade internacional fazia de Cabo Verde.

A agenda política do novo Estado são-tomense tinha também subjacente a luta contra o sub-desenvolvimento mas não foi definida nem executada com a proficiência verificada em Cabo Verde. Seja por razões exógenas, seja por razões endógenas, o que fez a diferença foram as realidades específicas e o ponto de partida dos dois territórios insulares na construção dos seus Estados independentes. Na realidade, os dois Estados, não obstante algumas similitudes, não operam sob as mesmas condições sociopolíticas, económicas e culturais. Com uma situação agrícola bem diferente, em São Tomé e Príncipe as antigas roças foram nacionalizadas escassos meses após a independência. Tratou-se de uma medida enquadrada no modelo nacional de orientação socialista baseado no princípio de que a terra é um recurso fundamental, propriedade do povo e sobretudo das populações que nela vivem (cf. Seibert 2001). Porém, estas empresas estavam sujeitas às regras do funcionamento do sistema capitalista, continuando a produzir para abastecer os principais mercados produtores de chocolate, todos localizados nos países centrais, nomeadamente na Europa. Embora as fragilidades dos novos gestores sejam indiscutíveis (Cardoso 2007), elas não são suficientes para explicar cabalmente o seu declínio e fracasso. Em termos técnicos, estas unidades encontravam-se em situação de falência, com as finanças depauperadas e as infraestruturas técnicas obsoletas. A política do novo Estado foi inspirada no princípio da gestão estatal do setor produtivo, basicamente centrado no cacau, com o objetivo de produzir mais, criar riqueza e, a partir daí, promover o desenvolvimento sustentável do país. Porém, a sua frágil capacidade, sobretudo a ausência de quadros com competência suficiente para a gestão dos escassos recursos disponíveis, a inexistência de uma administração pública eficiente e a depauperada situação financeira e técnica das empresas, aliada a fatores exógenos, nomeadamente a volatilidade de preços de exportação do cacau no mercado internacional, e o aumento exponencial dos preços de importação de muitos dos fatores que entram na cadeia de produção dos produtos exportáveis goraram todas as expectativas.

26 Para stp1 (diplomata), São Tomé e Príncipe iniciou o processo de construção do Estado dominado por "um grande vazio na definição de objetivos de desenvolvimento". Justificando as razões da sua expressão, afirmou que "não havia capacidade de gestão adequada e por isso as insuficiências se multiplicaram". Na sua perspetiva, "o poder instituído na altura foi preenchendo os diferentes setores do Estado com agentes do Partido-Estado, sem capacidade técnica e incapazes de gerirem empresas e organizações públicas complexas", em contraponto com o que se passava em Cabo Verde, em que, como reitera cv8 (economista, consultor sénior),

na altura da independência a maioria dos governantes cabo-verdianos eram quadros com formação média ou superior. Portanto havia alguma massa crítica e capacidade técnica instalada. Entre os que fizeram a luta armada, a sua representação no aparelho do governo era insignificante.

De igual modo, stp2 (consultor), caracterizando a situação de partida do processo de implementação de políticas públicas em São Tomé e Príncipe, afirmou que "ao contrário de Cabo Verde, São Tomé e Príncipe não estava convencido que a sua maior riqueza era o capital humano". Mais, e conquanto se possa reconhecer a importância do fator político na escolha dos responsáveis pelas empresas públicas - atendendo a que havia que romper com a propriedade privada e as lógicas e interesses a ela associados -, o que acabou por 
prevalecer foi o fator clientelar, fundado na proximidade familiar, partidária ou outra, sem tomar em consideração a competência técnica, relações estas que estão, como justamente assinala Seibert (2001: 485) profundamente enraizadas na sociedade local, remontando as suas origens às raízes da colonização. ${ }^{6}$ Ou seja, em São Tomé e Príncipe a regulação estatal parece assentar, segundo o definido por Médard (2000), numa estratégia política baseada na distribuição de bens públicos divisíveis, isto é, empregos, património, serviços e proteção em troca do apoio político. Os recursos controlados pela elite dirigente devem, em grande parte, ser alocados na sua rede de parentela e de clientes sob pena de, não o fazendo, fragilizar o seu próprio poder. Estamos, pois, perante relações sociais de tipo patrimonial solidamente enraizadas nas práticas sociais, dependendo esta neopatrimonialização do Estado do funcionamento duma rede densa e complexa de relações de patrocinato-clientelismo, em que cada cliente se serve dos recursos disponibilizados pelo patrono para criar a sua própria clientela (Thomson 2000: 111). ${ }^{7}$ Por outras palavras, não existia na elite dirigente uma lógica moderna de governo da coisa pública, no sentido weberiano [Cf. Weber 1993 (1922)], essencial para a formação de um "eu coletivo" (Aguiar 2009: 7) que permitisse desenhar um modelo de desenvolvimento assente nas realidades específicas do país. Daí a ausência de parâmetros, referências e mesmo de metas viáveis para a melhoria das condições de vida dos cidadãos santomenses, que acabaram por conduzir o país a um funcionamento completamente aleatório, atabalhoado e apático. A incapacidade de materializar ações concretas visando atingir objetivos definidos, tendo em vista a construção de um Estado auto-sustentável, faz com que São Tomé e Príncipe possa ser considerado como um caso paradigmático de "nãoação" (Parreira 2009: 13).

Perante este contexto, e como justamente afi rma stp3 (politólogo, antigo membro do governo santomense), "qualquer reflexão sobre as políticas públicas em São Tomé e Príncipe não pode ser feita fora do contexto da sua própria história". Na sua perspectiva, a mudança do paradigma do Estado colonial para o Estado pós-colonial na prática não provocou uma descontinuidade de ações, no que se refere a atitudes e comportamentos, o que quer dizer que o Estado pós-colonial em São Tomé e Príncipe continuou a ter muitas características do Estado colonial. Significa o mesmo que dizer que houve uma mudança de atores políticos, passando os são-tomenses a ocuparem o lugar deixado pelos portugueses, mas aqueles não tiveram conhecimento nem capacidade suficiente para procederem a uma mudança qualitativa do aparelho do Estado que permitisse eleger políticas públicas que fossem capazes de romper com a pobreza e a fragilidade das estruturas económicas. De certo modo, verificou-se em São Tomé e Príncipe o mesmo fenómeno observado por Ribeiro (2010: 130) em Moçambique. ${ }^{8}$ Longe de ser uma estrutura débil, o edifício político-administrativo erguido pelos portugueses estava solidamente enraizado. Assim, o aparelho de Estado santomense foi construído a partir do que existia, aproveitando a sua estrutura material, se bem que evacuada dos seus anteriores agentes, rapidamente substituídos pelo corpo de funcionários recrutado pelo novo poder político de entre os poucos trabalhadores escolarizados disponíveis, incluindo técnicos e elementos mais politizados para ocuparem os lugares de direção e chefia nos diversos níveis da cadeia hierárquica. Mas não só, à semelhança do verificado em Moçambique, o Estado pós-colonial adotou uma máquina autoritária e repressiva, tendo inibido a participação ativa da sociedade no seu próprio desenvolvimento. Este Estado acabaria por caminhar rapidamente para o seu próprio fracasso, face às reivindicações da sociedade. Descredibilizado e sem rumo, o Estado, menos de uma década após a 
independência, viu a sua legitimidade questionada, não encontrando apoio bastante nas diversas camadas sociais para o modelo político instituído.

Em síntese, em São Tomé e Príncipe faltou na fase inicial da independência uma liderança esclarecida. Não obstante as declarações de intenções e a elaboração oficial de políticas públicas, estas acabaram por não serem implementadas com a necessária eficiência. Quando se faz o balanço conclui-se pela ausência de resultados. Estavam assim criadas as condições necessárias para uma mudança substantiva do modelo de orientação governativa.

\section{Democracia parlamentar e mercado: mudança política e as políticas públicas em Cabo Verde e São Tomé e Príncipe}

Cumprida a primeira década de independência ocorre, tanto em Cabo Verde como em São Tomé e Príncipe, uma mudança radical em termos de organização política do regime que implicou uma redefinição da agenda política e das políticas públicas, sem que, porém, se tenha verificado uma alteração substancial em termos de resultados. De facto, enquanto em Cabo Verde a boa governação continuou a influenciar as políticas públicas, em São Tomé e Príncipe a mudança de sistema político não produziu um melhor desempenho.

31 A opção pela economia de mercado em Cabo Verde não afetou a implementação de políticas públicas vinculadas à formação técnica para a liderança do processo de desenvolvimento, à observância dos contratos internacionais e à promoção de programas de desenvolvimento ambiciosos. Um dos entrevistados (cv8, economista, consultor sénior) interpreta a materialização de políticas públicas em Cabo Verde, após a fase de realização de políticas de emergência, a dois níveis: (i) ao nível macro, composto por aquelas políticas propiciadoras de um ambiente favorável à aplicação de políticas sectoriais, nomeadamente a manutenção das contas externas sob vigilância permanente das autoridades públicas e controlo do défice público; (ii) ao nível micro, composto pelas políticas sectoriais. A realização com eficácia destas políticas tem sido crucial para a sustentabilidade de Cabo Verde. Na sua visão,

A manutenção das contas externas sob permanente vigilância das autoridades, num país pequeno e insular como Cabo Verde, onde o impacto externo é propenso a desestabilização e em que qualquer pequeno desequilíbrio externo é suficientemente forte para provocar grandes perturbações à economia interna, conduziu as autoridades cabo-verdianas a estarem atentas a duas coisas: ter as contas externas sob vigilância permanente porque a sua evolução positiva é o garante da satisfação dos compromissos externos (pagamento da dívida externa pagamento das importações, repatriamento dos recursos financeiros quando alguma atividade interna o requer); adoção de um apertado controlo sobre o défice, porque um défice exagerado impede que haja controlo sobre a inflação e impede o acesso ao crédito bancário, condições necessárias à expansão das atividades económicas (cv8, economista, consultor sénior).

Por outro lado, o país tem procurado desenvolver uma força de trabalho com qualificação e perfil adequados às suas necessidades e dinamizado a aquisição de competências por parte do empresariado nacional. Prosseguindo com cv8 (economista, consultor sénior), existe um consenso nacional em torno dos principais eixos de políticas públicas, o que faz com que, seja qual for o governo em função, a governação cabo-verdiana orientar-se-á através dos mesmos eixos na definição dos programas de dinamização económica e social 
do país. Com efeito, o Estado cabo-verdiano tem procurado: (i) o desenvolvimento do setor dos serviços, sendo de destacar o turismo; (ii) a manutenção da agricultura como garantia básica da segurança alimentar e emprego; (iii) o desenvolvimento da indústria de processamento de pescado.

O setor de turismo é, evidentemente, aquele que ganhou maior expressão após independência em Cabo Verde. ${ }^{9}$ Com um investimento que já ultrapassa os $20 \%$ do PIB, poderá atingir 50\% do PIB no período de 10 a 15 anos, se houver uma evolução favorável, sublinha cv8 (economista, consultor sénior). O serviço de shipping - serviços de carga e transporte marítimo - é outro setor que tem envolvido não só a construção de infraestruturas com capacidade operativa para manuseamento de cargas dos mais diversos tipos, como tem concentrado investimentos para, no futuro, conferir a cada ilha do arquipélago um porto com capacidade de transbordo e estabelecimento de ligações entre ilhas através de ferryboats modernos. Ainda no setor de prestação de serviços, Cabo Verde vem investindo no apoio à navegação aérea internacional e nas tecnologias de informação. $\mathrm{Na}$ área das novas tecnologias, está a organizar um moderno sistema de base de dados integrado para a administração pública. Já no domínio agrícola Cabo Verde tem procurado diversificar os investimentos, mormente em sistemas de poupança de água, em técnicas de produção mais avançadas e com maior rendimento, sem descurar a transformação e a comercialização. $O$ investimento na apresentação do produto, no seu transporte, na sua conservação e na sua certificação de qualidade tem permitido que entre o agricultor e o mercado se estabeleça paulatinamente um conjunto de intermediários que têm beneficiado com esta postura e têm contribuído para a incorporação de valor acrescentado ao produto. A indústria do processamento de pescado constitui outro dos setores que vem sendo implementado em Cabo Verde com sucesso. A perspetiva de Cabo Verde tem consistido em instituir uma indústria de processamento através de importação de matéria-prima, uma vez que o país não é sufi cientemente rico em pescado, não tem grande experiência de captura e nem possui uma frota pesqueira que sirva de base para uma captura em grande escala. Apesar da sua vasta zona económica exclusiva, com $734.265 \mathrm{Km} 2$, e $1.020 \mathrm{Km}$ de linha de costa, o potencial de recursos haliêuticos é estimado em apenas 36.000 a 44.000 toneladas. Todavia, a atividade pesqueira desempenha um importante papel social em Cabo Verde, contribuindo para o emprego e para a segurança alimentar (v. www.indp.cv).

Apesar de este cenário conter muitos elementos favoráveis, importa não ignorar os constrangimentos que condicionam Cabo Verde. Como afirma cv8 (economista, consultor sénior), "Cabo Verde possui um conjunto de fatores que condicionam o seu processo do desenvolvimento". Entre os mais importantes, aponta: (i) a descontinuidade geográfica; (ii ) ausência de água potável; (iii) ausência de cultura de desenvolvimento. A descontinuidade geográfica em Cabo Verde, com maior peso do que em São Tomé e Príncipe, faz com que as infraestruturas básicas imprescindíveis ao desenvolvimento do país tenham custos muito elevados. A ausência de água potável em muitas zonas do país repercute-se de forma negativa em todos os setores socioeconómicos e faz com que as soluções para o problema sejam muito custosas.

Por contraponto, em São Tomé e Príncipe permaneceu a crónica instabilidade social e política - marcada por eventos graves, como tentativas de golpe de Estado, a última das quais em fevereiro de 2009 -, a que se junta a incapacidade de se combater de modo eficiente a apropriação privada de bens e recursos do Estado. ${ }^{10}$ Assim, em São Tomé e Príncipe há ainda um longo percurso a percorrer na criação de condições básicas que 
sustentem um processo de formulação de políticas públicas, cuja implementação seja eficaz e capaz de proporcionar resultados e impactos positivos na sociedade. Acerca desta situação,

em São Tomé e Príncipe foi produzido todo um conjunto de documentos de política. Porém, o problema é que nenhuma das grandes iniciativas de políticas públicas que deveriam ser materializadas teve início, meio e fim. As coisas foram sempre ficando pelo meio e, desta forma, o que se constata hoje é que os conflitos políticos e institucionais não permitiram que qualquer política ou estratégia tivesse consequência. Portanto, o que tem que ser tomado como risco e um problema a resolver são estas querelas institucionais e só desta maneira poder-se-á encontrar mecanismos que permitam materializar de forma eficiente as políticas públicas e proceder ao seu balanço de forma consistente. Se tudo cai no início ou no meio torna-se difícil equacionar devidamente se os objetivos foram ou não alcançados porque nada foi feito como inicialmente projetado. As políticas públicas não têm sido assumidas e apropriadas e, além de mais, muitas delas foram programadas de costas viradas para a população. $O$ que é preciso é que o país e suas instituições funcionem de forma regular com planos e programas e no fim de cada mandato possa ser avaliado o desempenho de cada instituição (stp5, professor universitário).

A sistemática instabilidade política e social tem impedido a realização de políticas públicas consistentes. Procurando ilustrar as consequências daqui decorrentes, afirma que

nos períodos de menor instabilidade são definidos os grandes eixos de políticas públicas, tais como GOP [Grandes Opções do Plano], planos anuais, planos e estratégias sectoriais, mas que acabam por não ser devidamente implementadas com sucesso devido a ausência de estabilidade governativa. Além disso, não existe uma boa articulação entre as grandes orientações estratégicas, os planos anuais e os respetivos OGE [Orçamento Geral do Estado] nacionais em São Tomé e Príncipe (oi2, português, consultor internacional).

Os OGE, entendidos como o instrumento fundamental das políticas públicas no seu conjunto, definindo as prioridades, quer para as despesas correntes, quer para as despesas de capital, cujos recursos disponíveis podem ser internos - receitas, impostos e outras cobranças não tributáveis - e receitas externas - donativos, empréstimos e APD disponibilizados pelos parceiros de desenvolvimento -, enfrentam, deste modo, e de forma permanente, dificuldades na sua implementação. Os dados estatísticos - muito abundantes e fiáveis para Cabo Verde, mais escassos e menos rigorosos para São Tomé e Príncipe - validam, a seu modo, os discursos destes atores sociais. Medidas as políticas públicas pela ótica da pobreza, reconhece-se de forma inequívoca as diferenças entre estes países. Conquanto em Cabo Verde persistam bolsas dramáticas (v. Nascimento 2009), a percentagem da população a viver em pobreza extrema diminuiu de $49 \%$ em 1988-89 para $37 \%$ em 2001-02, para $27 \%$ em 2007 e para $24 \%$ em 2010. O BM sublinha que esta é uma importante conquista que só foi possível devido ao rápido crescimento da renda per capita $^{11}$. Este país da África ocidental é hoje, em certa medida, o resultado de uma visão concebida no início da independência, alicerçada numa agenda política cuidada e que permitiu a materialização de políticas públicas à medida da realidade específica do arquipélago. Ainda que os números possam esconder muito e necessitarem sempre de interpretação avisada e crítica, são incontroversos os ganhos que Cabo Verde obteve nos seus índices sociais de desenvolvimento, permitindo assim um cumprimento satisfatório dos ODM. Como se escreve no relatório de progresso, publicado em 2010, "se a tendência da evolução dos dados do país referentes à realização dos ODM persistir, as probabilidades 
de realização de grande parte das metas dos ODM no horizonte pré-estabelecido são grandes" (Disponível em: http://www.un.cv/fi les/MDGReportCV.pdf). ${ }^{12}$

Já para São Tomé e Príncipe, apesar da referida escassez de dados estatísticos devidamente organizados e atualizados não permitir uma análise circunstanciada e fiável da situação, é indiscutível admitir que o Estado tem sido

incapaz de reduzir a pobreza. Como vem expresso nas Perspetivas Económicas para São Tomé e Príncipe no relatório da OCDE/BAD $2011^{13}$

a pobreza, estimada em cerca de $54 \%$, em 2009 , continua muito difundida em áreas rurais e na periferia das zonas urbanas. A busca de oportunidades de emprego promove a migração urbana, o que coloca uma pressão crescente sobre as infraestruturas da capital e alimenta o setor informal, estimado em $63 \%$ da economia.

Em São Tomé e Príncipe, a pobreza manifesta-se com acuidade nas comunidades dos pescadores e de agricultores, particularmente nas pessoas idosas, crianças abandonadas e mulheres chefes de família. $O$ aumento do número de crianças abandonadas, meninos de rua, o aumento galopante dos preços de bens de primeira necessidade, o crescente fenómeno da prostituição, a utilização desastrosa dos recursos naturais e humanos, a má qualidade das habitações são somente alguns sinais claros da multidimensionalidade da pobreza. Dados referentes a 2009 indicam que a percentagem da população com múltiplas carências atingiu $34,5 \%$ com uma intensidade de privação a rondar os $44,7 \%$. A população vulnerável à pobreza atingiu $24,3 \%$ e a população em pobreza grave ronda os $10,7 \%$. A proporção de pessoas com privações de serviços ambientais é também alta, sendo que $29,6 \%$ precisam de saneamento melhorado e $31,3 \%$ de combustíveis modernos. A percentagem da população a viver com menos de 1,25 dólares por dia atingiu $28,6 \% \mathrm{em}$ 2009 (v. Relatório de Desenvolvimento Humano 2011).

\section{Considerações finais}

41 Após vários séculos de colonização, a prioridade de Cabo Verde e São Tomé e Príncipe pós-independência centrou-se na elaboração e concretização de políticas públicas que contribuíssem para minorar e, se possível, superar os múltiplos problemas provocados pela sua posição periférica e historicamente subordinada no quadro do sistema mundial capitalista.

Como vimos e é reconhecido nos discursos dos nossos entrevistados, os resultados são muito desiguais. Cabo Verde, contra muitas expectativas, incluindo as da elite dirigente nos alvores da independência, deu passos significativos nas mais diversas áreas que concorrem para o bem-estar social e o incremento económico, com manifestos reflexos na evolução da sua posição nos principais indicadores internacionais, como exprime o índice de desenvolvimento humano do Programa das Nações Unidas para o Desenvolvimento, demonstrando desta forma a importância não só do bom desenho de políticas públicas mas também o da sua adequada implementação. A estabilidade 
Quadro 1. Política, economia e políticas públicas em Cabo Verde e S. Tomé (síntese comparativa)

\begin{tabular}{|c|c|c|c|c|}
\hline Período & \multicolumn{2}{|c|}{ 1975-1989 } & \multicolumn{2}{|c|}{ 1990-2012 } \\
\hline 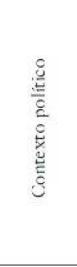 & $\begin{array}{l}\text { Fimergencial, com orientação } \\
\text { socialista fraca, partido único, } \\
\text { um corpo de funcionários } \\
\text { pequeno mas razoavelmente trei- } \\
\text { nado e competente. Estabilidade } \\
\text { política, com uma definição } \\
\text { rigorosa e aplicação persistente } \\
\text { das políicas públicas. Prestigio } \\
\text { do Estado. }\end{array}$ & $\begin{array}{l}\text { Revolucionário com forte retó- } \\
\text { rica socialista, partido único, } \\
\text { extrema carência de quadros e } \\
\text { pessoal técnico para assegurar } \\
\text { as funções nos aparelhos do } \\
\text { Estado. Instabilidade política. } \\
\text { Descredibilizaçāo do Estado. }\end{array}$ & $\begin{array}{l}\text { Democracia parlamentar. } \\
\text { Estabilidade politica. }\end{array}$ & $\begin{array}{l}\text { Democracia parlamentar. } \\
\text { Instabilidade politica, com golpes } \\
\text { (e tentativas) de golpe de Fstado, } \\
\text { mantendo-se as forças armadas } \\
\text { como um ator (desestabilizador) } \\
\text { da maior importância. }\end{array}$ \\
\hline 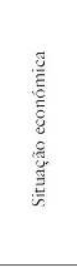 & $\begin{array}{l}\text { Problemas económicos múlti- } \\
\text { plos, fragilidade do ecossistema. } \\
\text { Carências alimentares extremas. }\end{array}$ & $\begin{array}{l}\text { Economia muito dependente da } \\
\text { produção e exportação de cacau, } \\
\text { cujo preço está sujeito a grandes } \\
\text { oscilaçôes no mercado interna- } \\
\text { cional. Decadência do modelo } \\
\text { produtivo baseado nas roças. }\end{array}$ & $\begin{array}{l}\text { Liberalização da economia, } \\
\text { privatização das empresas, dimi- } \\
\text { nuição da presença do Estado na } \\
\text { economia. Integração dependente } \\
\text { na economia-mundo capitalista. } \\
\text { Crescimento económico e melho- } \\
\text { ria significativa dos indicadores } \\
\text { de bem-estar e desenvolvimento } \\
\text { humanos. }\end{array}$ & $\begin{array}{l}\text { Liberalização da economia, } \\
\text { privatização das empresas, dimi- } \\
\text { nuição da presença do Estado na } \\
\text { economia. Integração dependente } \\
\text { na economia-mundo capitalista. } \\
\text { Persistência da pobreza genera- } \\
\text { lizada, dependência extrema da } \\
\text { ajuda internacional, incapacidade } \\
\text { de diversificação da economia. }\end{array}$ \\
\hline 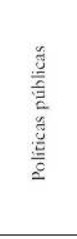 & $\begin{array}{l}\text { Definição clara dos objetivos: } \\
\text { educaçāo como eixo fundamental } \\
\text { da açâo do Fstado. Ação "emer- } \\
\text { gencial" a nível da segurança } \\
\text { alimentar. Intervenção relevante } \\
\text { no campo do desenvolvimento } \\
\text { rural, pescas, transportes, comu- } \\
\text { nicaçôes e turismo. }\end{array}$ & $\begin{array}{l}\text { Incerteza, não definição de obje- } \\
\text { tivos e metas, resultados medio- } \\
\text { cres, predomínio dos interesses } \\
\text { particulares, sustentados por } \\
\text { redes clientelares em prejuízo do } \\
\text { interesse público. Estado mar- } \\
\text { cado pela "nāo-ação". }\end{array}$ & $\begin{array}{l}\text { Manutençāo dos objetivos defi- } \\
\text { nidos na fase anterior, com desta- } \\
\text { que para a educação e o turismo. }\end{array}$ & $\begin{array}{l}\text { Elaboraçāo de documentos orien- } \\
\text { tadores dos eixos fundamentais } \\
\text { das políticas públicas ( } \nu \text {.g., GOP } \\
\text { e outros planos), sem reflexos } \mathrm{em} \\
\text { políticas públicas concretas. }\end{array}$ \\
\hline & Cabo Verde & S. Tomé e Principe & Cabo Verde & S. Tomé e Príncipe \\
\hline
\end{tabular}

43 governativa, a capacidade das elites e a existência de técnicos qualificados têm permitido a este país uma melhor absorção dos recursos disponibilizados pela comunidade internacional para o desenvolvimento. Já em São Tomé e Príncipe o trajeto foi bem mais incerto e turbulento, feito de fracassos recorrentes. Por razões variadas e complexas, envolvendo causas externas e internas acima amiúde discutidas, nas quais se devem destacar as que se prendem com a composição de classes, a falta de quadros e outros recursos humanos necessários à boa execução das políticas públicas, as práticas clientelares e a inexistência de um sentido moderno de Estado, a todo o tempo jogadas num quadro de instabilidade política aguda devido às lutas pelo controlo das rendas e outros recursos entre as diversas fações que compõem a elite santomense, o país mostrou-se incapaz de dar passos positivos na resolução dos seus principais problemas económicos e sociais, não obstante as intenções e as inúmeras políticas públicas concebidas mas raramente implantadas, fazendo com que se possa olhar para este Estado como um caso evidente de "não-ação" (v. quadro 1).

Em suma, se os resultados em Cabo Verde podem ser considerados satisfatórios, sobretudo quando comparados com os alcançados por São Tomé e Príncipe, é preciso reconhecer que o país está longe de atingir a tão almejada sustentabilidade do seu próprio desenvolvimento. Não obstante a vontade explícita demonstrada pelos governantes na procura de soluções de bem-estar para a sociedade cabo-verdiana, as ações empreendidas ao longo das últimas quase quatro décadas de independência não foram suficientes para reduzir substancialmente a pobreza e desatar os nós que atam o país, tal com acontece em São Tomé e Príncipe, a uma situação de dependência estruturada. Independentemente dos resultados, há que sublinhar que a implementação de políticas públicas nestes dois países insulares não está ausente de riscos e constrangimentos. A base financeira de sustentação das políticas públicas é deficitária, continuando as mesmas muito dependentes da APD. 


\section{BIBLIOGRAPHY}

AFRICAN ECONOMIC (2010), [Online] Disponível em: http://www.africaneconomicoutlook.org/ po/in-depth/public-resource-mobilisation-and-aid/ [consultado em 19 de julho de 2010].

AGUIAR, João Valente (2009), “A classe social como processo: o conceito de formação da classe trabalhadora", Configurações, 5/6: 75-100.

BALDACCHINO, Godfrey (2008), Studying Islands: Some Epistemological and Methodological Challenges to the Pursuit of Islands Studies, Charlottetown, University of Prince Edward Island.

BALDACCHINO, Godfrey. (2010), "Imigrantes, turistas e outros e outros: 'venha visitar, mas não permaneça"- a ameaça de invasão para as sociedades insulares", in M. Lucinda Fonseca (coord.), Aproximando Mundos: Emigração, Imigração e Desenvolvimento em Espaços Insulares (Atas da Conferência Internacional), Lisboa: Fundação Luso-Americana para o Desenvolvimento: 63-86.

BARBOSA, José (2002), Políticas públicas e estratégia de desenvolvimento para São Tomé e Príncipe. Lisboa: Instituto Superior de Economia e Gestão da Universidade Técnica de Lisboa (tese de mestrado).

BASS, Stephen \& Barry Dalal-Clayton (1995), "Small Islands States and Sustainable Development: Strategic Issues and Experience", Environmental Planning Issues, ํㅡㅇ.

BRESSER-PEREIRA, Luís Carlos (2008), "Desenvolvimento Económico e Revolução Capitalista" (texto para Discussão EESP/FGV 170, in www.fgvsp.br/economia).

BRIGUGLIO, Lino, Bishnodat Persaud e Richard Stern (2005), Pequenos Estados Insulares. Para uma Estratégia de Desenvolvimento dos Pequenos Estados voltada para o Exterior. Washington: BM e FMI. BOURDIEU, Pierre (1999), A dominação masculina, Oeiras: Celta.

BRITO, R. Brígida (2005), o Desenvolvimento para além do Petróleo, o exemplo do Turismo em São Tomée Príncipe, Aveiro: Universidade de Aveiro.

CABO VERDE, Relatório de Progresso (2011), [Online] Disponível em: http://www.un.cv/files/

CARCANHOLO, Marcelo Dias \& Marisa Amaral Silva (2009), “A superexploração do trabalho em economias periféricas dependentes”, Katálysis, vol. 12, nº 2: 216-225.

CARDOSO, Manuela (2007), Cabo Verde e São Tomé e Príncipe: educação e infraestruturas como fatores de desenvolvimento, Porto: Afrontamento.

CHOWDHURY, Anwarul (2005), “Small Islands, Big potential”, DESA News, vol. 9, n.1, (Disponível em: http://www.un.org/esa/desa/desaNews/desa91.html).

COUTO, Carlos Ferreira (2001), Estratégias familiares de subsistências rurais em Santiago de Cabo Verde. Lisboa: Instituto da Cooperação Portuguesa.

DAVIDSON, Basil (1988), As ilhas afortunadas: um estudo sobre a África em transformação. Lisboa: Caminho.

EASTERLY, William e Aart Kraay (1999), Small States, Small Problems? Washington, BM Development Research Group - Macroeconomics and Growth. 
FACULDADE DE LETRAS UNIVERSIDADE DO PORTO (2011), [Online] Disponível em http:// ler.letras.up.pt/uploads/ficheiros/7018.pdf [consultado em 3 de outubro de 2011].

INDP, Instituto Nacional do Desenvolvimento e Pescas (2011), [Online] Disponível em: www.indp.cv [consultado em 12 de outubro de 2011].

JALAN, Bimal (1982), Problems and Policies in Small Economies, Nova Iorque: Croom Helm.

KALY, Ursula, Craig Pratt e Russel Howorth (2002), "Towards managing environmental vulnerability in Small Island Developing States (SIDS)”, in Sopac - Miscellaneous Report 461.

KING, Russel (2010), “A Geografia, as Ilhas e as Migrações numa era de mobilidade global - in Aproximando Mundos, Emigração, Imigração e Desenvolvimento em espaços insulares”, in M. Lucinda Fonseca (coord.), Aproximando Mundos: Emigração, Imigração e Desenvolvimento em Espaços Insulares (Atas da Conferência Internacional), Lisboa: Fundação Luso-Americana para o Desenvolvimento: 27-62.

LOPES, José Vicente (2002), Os bastidores da Independência, Cidade da Praia: Splen.

MÉDARD, Jean-François (2000), “Clientélisme politique et corruption”, Tiers Monde, XLI (161): 75-87.

MENEZES, Aires Bruzaca (2003), Implicações socioeconómicas da exploração do petróleo em São Tomé e Príncipe, Lisboa, Instituto Superior de Economia e Gestão da Universidade Técnica de Lisboa (tese de mestrado).

MENEZES, Aires Bruzaca (2012), Estado, políticas públicas e desenvolvimento: Cabo Verde e São Tomé e Príncipe. Vila Real, Universidade de Trás-os-Montes e Alto Douro (tese de doutoramento).

MDGReportCV.pdf [consultado em 12 de outubro de 2011]. http://www.ine.cv/actualise/ dadostat/fi les/64fc95ae-6380-43f9-afff2556e7432f2aevolu\%C3\%A7\%C3\%A3o\%20da\%20procura\% 20turistica\%20em\%20cabo\%20verde\%20segundo\%20ano,\%202000\%20a\%202011.pdf [consultado em 30 de abril de 2013].

NASCIMENTO, Augusto (2009), "Pobreza..., claro que nós temos...: apontamentos para a análise da consciência institucional em torno da pobreza e da microviolência em contextos caboverdianos", in Udelsmann Rodrigues e A. Bénard da Costa (orgs.) Pobreza e Paz nos PALOP, Lisboa: Sextante: 247-274.

PEREIRA, Aristides (2003), Uma luta, um partido, dois países: Guiné-Bissau e Cabo Verde; Lisboa: Círculo de Leitores.

PEREIRA, Daniela de Almeida e Enrique Martinéz Galán (2009), A Vulnerabilidade dos Pequenos Estados em Desenvolvimento: O Caso Particular dos Pequenos Estados Insulares em Desenvolvimento, Lisboa: Instituto Português de Apoio ao Desenvolvimento.

PARREIRA, José Manuel Rocha (2009), Organizações de Base Comunitária: Que papel no Conceito e Implementação do Desenvolvimento a partir de baixo, Lisboa: Instituto Superior de Economia e Gestão da Universidade Técnica de Lisboa (tese de mestrado).

RIBEIRO, Fernando Bessa (2010), Entre martelos e lâminas: dinâmicas globais, políticas de produção e fábricas de caju em Moçambique, Porto: Afrontamento

SEIBERT, Gerhard (2001), Camaradas, clientes e compadres: colonialismo, socialismo e democratização em São Tomé e Príncipe, Lisboa: Vega.

SILVA, Manuel Carlos (1988), "Camponeses e patronos: o caso de uma aldeia minhota", Cadernos de Ciências Sociais: 7, 51-80. 
SILVA, Manuel Carlos (1993), “Camponeses, mediadores e Estado”, Análise Social, vol. XXVIII, 122: 489-521.

SOBRAL, José Manuel \& Pedro Tavares Almeida (1982), “Caciquismo e poder político: reflexões em torno das eleições de 1901”, Análise Social, XVIII (72-74): 649-671.

TAGLIONI, François (2006), “Les petits espaces insulaires face à la variabité de leur insularité et de leur statut politique”, Les Annales de Géographie, 끄6 652, 664-687.

TAGLIONI, François (2010), “L’insularisme: une rhétorique bien huilée dans les petits espaces insulaires", in Olivier Sevin et al. (dir), Comme un parfum d'île, Paris: Presse Universitaire ParisSorbonne (PUPS): 421-435.

THOMSON, Alex (2000), An introduction to African politics, Londres: Routledge.

TOLENTINO, André Corsino (2006), Universidade e Transformação Social nos Pequenos Estados em Desenvolvimento: O Caso de Cabo Verde. Lisboa, Faculdade de Psicologia e de Ciências da Educação da Universidade de Lisboa (tese de doutoramento).

WALLERSTEIN, Immanuel (2002), Após o liberalismo: em busca da reconstrução do mundo, Petrópolis: Vozes.

WEBER, Max [1993 (1922)], Economía y sociedad: esbozo de sociología comprensiva, Cidade do México: Fondo de Cultura Económica.

WORSLEY, Peter (1964), The Third World, Londres: Weidenfeld \& Nicolson.

\section{NOTES}

1. O limite de 1,5 milhões foi adotado também pelo Banco Mundial (BM) para definir as pequena economias insulares (Taglioni 2006: 5).

2. São vários os exemplos, apontados por King (2010) e outros teóricos de estudos insulares (Bass \& Dalal-Clayton 1995, Briguglio 1995, Baldacchino 2010), que justifi cam a presença de tais fatores de constrangimentos, a saber: (i) o caráter limitado do mercado local de bens e serviços; (ii) a reduzida diversificação de produção local em consequência da escassez dos recursos; (iii) o elevado custo associado ao transporte (custos de insularidade) tanto das importações como das exportações; (iv) a vulnerabilidade face aos preços praticados nos mercados mundiais; (v) o elevado risco de perda de colheitas em resultado da exposição a catástrofes naturais; (vi) as limitações estruturais do mercado local de trabalho, cuja lista não é definitiva.

3. Witter et al. defi nem o conceito de vulnerabilidade económica "como a propensão de uma economia para o dano causado por fatores externos, e consideram que, sob certas circunstâncias, esta vulnerabilidade pode ameaçar a viabilidade económica" (apud Pereira \& Galán 2009: 89). Em termos específicos, Warriner \& Milne sublinharam que "a vulnerabilidade económica continua a ser uma característica estrutural [sobretudo] das ilhas de plantação, não só por causa da sua escassa diversificação produtiva e da sua dependência face aos preços praticados nos mercados mundiais de matéria-prima como também devido à concentração dos meios de produção nas mãos de 'plantocracias locais' ou de empresas multinacionais" (apud King 2010: 43).

4. Em 2000, a ONU, ao analisar os maiores constrangimentos mundiais ao desenvolvimento, estabeleceu oito ODM, a serem atingidos num prazo de 25 anos, a saber: (i) erradicar a pobreza extrema e a fome; (ii) alcançar a educação primária universal; (iii) promover a igualdade de género e capacitar as mulheres; (iv) reduzir a mortalidade infantil; (v) melhorar a saúde materna; (vi) combater o VIH/sida, a malária, a tuberculose e outras doenças; (vii) assegurar a 
sustentabilidade ambiental; (viii) desenvolver uma parceria global para o desenvolvimento (ODM 2011). Os 8 ODM integram 18 metas e cerca de 40 indicadores.

5. Trata-se da Empresa Pública de Abastecimento, já extinta, que tinha, entre outras atribuições, a responsabilidade pela importação, distribuição e comercialização dos produtos essenciais à economia do Estado, nomeadamente alimentares, a exportação de produtos nacionais e garantir preços justos no mercado interno ao produtor e ao consumidor.

6. O conceito de clientelismo, bem conhecido da antropologia e da sociologia rurais, articula-se com o seu contraponto, o do patrocinato, "mecanismo de vinculação e coerção psicosssocial e, por vezes, física, no qual se verifica a servilidade e a dependência do cliente face a uma outra pessoa social e/ou politicamente influente denominada patrono" (Silva 1988: 54). É uma relação assimétrica, na qual o patrono concede favores e presta alguns serviços em troca do apoio do cliente. Em termos político-administrativo, o patrocinato assume a forma de caciquismo, sendo o cacique um intermediário entre os segmentos sociais locais e o Estado que os engloba, dela retirando benefícios pessoais. Em troca dos votos, indispensáveis à reprodução e legitimação das instituições políticas, presta um conjunto de serviços - os "favores" - à população (Sobral \& Almeida 1982, Silva 1993).

7. Na sua densa teorização sobre o patrimonialismo, Weber [1993 (1922): 753ss] traz à existência os seus mecanismos de funcionamento. No seu entender, a organização política patrimonial ancora-se num conjunto alargado e muito vasto - um "caos" no dizer do autor - de privilégios e obrigações subjetivos que ligam o chefe, o funcionário e o dominado, dando lugar a uma ação comunitária que nada tem a ver com as categorias modernas de direito público e que tão-pouco tem a ver com o modo de funcionamento do Estado no sentido que atualmente lhe é dado. 0 próprio poder é visto como um privilégio, sendo os recursos geridos e distribuídos numa base de proximidade e confiança pessoais que unem o chefe aos que dele dependem. Sobretudo na sua versão patriarcal, a legitimidade do patrimonialismo depende da satisfação dos que são súbditos por via da distribuição de propriedade e outros benefícios, sempre feitos, sublinhe-se, segundo critérios de proximidade relacional ou outros que não se enquadram nos pressupostos modernos de atuação do Estado.

8. Como aponta Ribeiro (2010: 130), para o caso moçambicano, apesar do voluntarismo, as estruturas, a começar pelo caráter "colonial" da economia (Worsley 1964: 241), e os hábitos não se removem por um ato jurídico ou pela mera enunciação da vontade dos dirigentes. Aliás, é necessário enfatizar que as forças progressistas não são imunes à incorporação das estruturas e das disposições que as dominam, fazendo estas sentir-se sob a proposta de uma ordem moral que não deixa, no limite, de incorporar a velha ordem conservadora (cf. Bourdieu 1999).

9. Entre outros documentos disponibilizados pelo Instituto de Estatística de Cabo Verde, v. http://www.ine.cv/actualise/dadostat/files/64fc95ae-6380-43f9-afcf2556e7432f2aevolu\%C3\%A7\% C3\%A3o\%20da\%20procura\%20turistica\%20em\%20cabo\%20verde\%2segundo\%20ano,\%202000\%20a \%202011.pdf.

10. Entre outros casos bem conhecidos, destacam-se: (i) a falência da Caixa Nacional de Poupança e Crédito provocada pela fraude, desorganização e violação das regras bancárias; (ii) a tentativa de fraude com falsos títulos de tesouro no valor de 500 milhões de dólares norte-americanos, que levou à demissão do governador e do administrador do Banco Central em março de 1999; (iii) os desvios de fundos de contrapartida do Gabinete de Gestão das Ajudas, com o envolvimento de proeminentes fi guras políticas, tendo conduzido à prisão os membros da Direção dessa instituição pública; (iv) o desvio de cinco milhões de francos franceses numa conta à ordem do Banco Nacional de São Tomé e Príncipe para o Banque Nationale de Paris, do qual resultou a prisão um alto funcionário da instituição fi nanceira santomense (cf. Seibert, in http:// ler.letras.up.pt/uploads/ficheiros/7018.pdf).

11. Ver http://web.worldbank.org/WBSITE/EXTERNAL/COUNTRIES/AFRICAEXT/ CAPEVERDEEXTN/0,menuPK:349633 pagePK:141132 piPK:141107 theSitePK:349623,00.html. 
12. Ver também http://web.worldbank.org/WBSITE/EXTERNAL/COUNTRIES/AFRICAEXT/ CAPEVERDEEXTN/0,menuPK:349633 pagePK:141132 piPK:141107 theSitePK:349623,00.html).

13. Ver http://www.africaneconomicoutlook.org/po/in-depth/public-resource-mobilisationand-aid/

\section{ABSTRACTS}

Cabo Verde e São Tomé e Príncipe são dois pequenos Estados insulares de colonização portuguesa. Desde a independência, em 1975, que procuram as melhores soluções para superarem os múltiplos problemas económicos e sociais com que se confrontam. Este artigo examina a agenda política e as políticas públicas engendradas nestes dois países africanos, procurando demonstrar que a compreensão das diferenças, sucessos e, sobretudo, fracassos, não pode ser desligada do contexto histórico, dos constrangimentos externos e das dinâmicas sociopolíticas internas.

Cape Verde and Sao Tome and Principe are two small island states of Portuguese colonization. Since their independence, in 1975, they are seeking the best solutions to overcome their economic and social problems. This article examines the political agenda and the public policies engendered in these two African countries, looking for understanding the differences, successes and, especially, the failures, which cannot be divorced from the historical context, external constraints and internal sociopolitical dynamics.

Cap-Vert et Sao Tomé-et-Prince sont deux petits Etats insulaires de colonisation portugaise. Depuis l'indépendance, en 1975, ils sont à la recherche de meilleures solutions pour surmonter leurs problèmes économiques et sociaux. Cet article examine l'agenda politique et les politiques publiques engendrées dans ces deux pays, et cherche à comprendre les différences, les réussites et, en particulier, les échecs, qui ne peuvent être dissociés du contexte historique, des contraintes externes et des dynamiques sociopolitiques internes.

\section{INDEX}

Mots-clés: état insulaire, Cap-Vert, Sao Tomé-et-Principe, politiques publiques, dépendance, développement

Keywords: island states, Cape Verde, Sao Tome and Principe, public policy, dependency, development

Palavras-chave: estados insulares, Cabo Verde, São Tomé e Príncipe, políticas públicas, dependência, desenvolvimento

\section{AUTHORS}

\section{AIRES BRUZACA DE MENESES}

Economista

bruzaca@portugalmail.pt 


\section{FERNANDO BESSA RIBEIRO}

Professor na Escola de Ciências Humanas e Sociais Universidade de Trás-os-Montes e Alto Douro e Centro de Investigação em Ciências Sociais da Universidade do Minho fbessa@utad.pt

\section{ARTUR CRISTÓVÃO}

Professor na Escola de Ciências Humanas e Sociais Universidade de Trás-os-Montes e Alto Douro e Centro de Estudos Transdisciplinares para o Desenvolvimento

acristov@utad.pt 